\title{
Desafios para a gestão de projetos urbanos com elevada complexidade: análise do Programa Integrado Entrada da Cidade em Porto Alegre, RS
}

Challenges of managing highly complex urban projects: analysis of the integrated city entrance program in Porto Alegre, RS

\section{Patrícia André Tillmann \\ Maria Conceição Barletta Scussel \\ Carlos Torres Formoso \\ Luciana Inês Gomes Miron}

Patrícia André Tillmann Núcleo Orientado à Inovação da Edificação Universidade Federal do Rio Grande do Sul Rua Osvaldo Aranha, 99, 30 andar, Centro Porto Alegre - RS - Brasil CEP $90035-190$ Tel.: (51) 3308-3518 E-mail: patriciatillmann@gmail.com

Maria Conceição Barletta Scussel Núcleo Orientado à Inovação da Edificação Universidade Federal do Rio Grande do Sul E-mail: scussel@ufrgs.br

Carlos Torres Formoso Núcleo Orientado à Inovação da Edificação Universidade Federal do Rio Grande E-mail: formoso@ufrgs.br

Luciana Inês Gomes Miron Núcleo Orientado à Inovacão da Edificação Universidade Federal do Rio Grande do Sul

E-mail: luciana.miron@ufrgs.br

Recebido em 18/04/11 Aceito em 04/08/11

\section{Resumo}

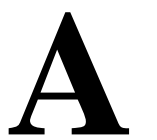

tualmente, as práticas de gestão de projetos vêm sendo amplamente criticadas por não oferecer suficiente suporte para lidar com as características de projetos com elevada complexidade. O presente artigo tem como objetivo apontar as dificuldades de gerenciar um projeto urbano com elevada complexidade, assim como os entraves para a introdução de práticas adequadas para a gestão de projetos desta natureza no contexto do setor público. Foi realizado um estudo de caso no Programa Integrado Entrada da Cidade (PIEC), em Porto Alegre - RS, cujo objetivo foi a reestruturação urbana de uma ocupada por assentamentos irregulares. Através deste estudo, pôde-se compreender melhor os aspectos que caracterizam a complexidade de projetos urbanos. Constatou-se que o modelo de gestão utilizado no Programa baseia-se em pressupostos de uma visão mecanicista, oferecendo pouco suporte para lidar com as características de um projeto com alta complexidade, tais como o elevado grau de interdependência entre ações, a multiplicidade de agentes intervenientes, além da alta suscetibilidade às influências do ambiente externo. O estudo aponta para a necessidade do desenvolvimento de mecanismos gerenciais mais adequados para projetos com estas características, que levem em consideração a interdependência entre ações e a necessidade do trabalho em equipe.

Palavras-chave: Gestão de projetos. Projetos complexos. Projetos urbanos. Habitação de interesse social.

\section{Abstract}

The traditional managerial approaches used in complex projects have been widely criticized for not offering support to deal with the characteristics of highly complex projects. The aim of this article is to point out the difficulties of managing a highly complex urban project, as well as to identify the barriers for introducing suitable practices for managing projects in the public sector. A case study was carried out in the Integrated City Entrance Program (PIEC) that aims to regenerate an area currently occupied by irreqular settlements. This study provided an understanding the main characteristics of urban complex projects. The results indicate that this project have adopted a managerial model that is based on a mechanicist perspective, offering poor support to deal with complexity issues, such as the interdependency between actions, the multiplicity of stakeholders and a high susceptibility to external events. The study identifies a need to develop adequate managerial mechanisms for projects with such characteristics, which take into consideration the interdependency between actions and the need for teamwork.

Keywords: Project management. Complex projects. Urban projects. Social projects. 


\section{Introdução}

Projetos $^{1}$ que visam a grandes mudanças muitas vezes falham em atingir os benefícios vislumbrados em sua concepção, não tanto pela falta de capacidade técnica, mas principalmente pela dificuldade de gerenciar a elevada complexidade existente (THORP, 1998; BARTLETT, 2006). Segundo Thorp (1998), tal complexidade geralmente não é levada em consideração nas tradicionais abordagens de gestão de projetos, cuja ênfase é dada à análise de custos, tempo de execução e conformidade em relação às especificações, e na adoção de instrumentos e procedimentos padronizados (WINTER et al., 2006).

$\mathrm{Na}$ visão convencional de gestão de projetos, considera-se que um conjunto de atividades sequenciais é necessário para que os objetivos (predefinidos) de um projeto sejam alcançados, sendo o foco da gestão voltado ao planejamento e ao controle dessas atividades, e à remoção ou redução de incertezas que possam afetar a conclusão das metas preestabelecidas (ATKINSON; CRAWFORD; WARD, 2006; WINTER et al., 2006; KOSKELA; HOWELL, 2002). Entretanto, essas práticas inserem-se em um modelo um tanto mecanicista e cartesiano, que vem sendo criticado por não lidar adequadamente com a natureza complexa dos projetos, além de sugerir um tratamento uniforme a projetos em contextos muito distintos (WINTER et al., 2006).

O presente artigo tem como objetivo apontar as dificuldades de gerir um projeto urbano com elevada complexidade, assim como os entraves para a introdução de práticas adequadas para a gestão de projetos dessa natureza no contexto do setor público. A pesquisa envolveu a realização de um estudo de caso no Programa Integrado Entrada da Cidade (PIEC), em Porto Alegre, RS. O critério de seleção utilizado para a escolha deste estudo foi o elevado impacto em seu entorno urbano, assim como por envolver um amplo conjunto de ações interdependentes, que deveriam ser implementadas simultaneamente para que os objetivos principais do Programa sejam atingidos.

Com seu início no final da década de 90, o PIEC visa melhorar as condições de vida de uma população que vive atualmente em assentamentos irregulares e precários localizados em uma zona de risco, próximo a faixas de domínio de rodovias,

\footnotetext{
${ }^{1} \mathrm{O}$ sentido da palavra "projeto" neste artigo corresponde ao termo "project", em inglês. Um termo substituto comumente utilizado na língua portuguesa é "empreendimento". Entretanto devido ao crescente uso dos termos "projeto" e "gestão de projetos" na literatura nacional referentes ao tema, optou-se por utilizar as palavras "projetos" e "programas".
}

facilmente alagável e sob redes de alta tensão. O foco desse programa é a reestruturação urbana e a recuperação ambiental da referida zona, que se localiza no entorno do principal acesso à cidade. Através da implementação do PIEC, a previsão é atender mais de $12 \%$ do déficit habitacional da cidade, estimado em torno de 30.000 domicílios. Entretanto, o PIEC parte de um pressuposto que o diferencia das tradicionais formas de intervenção habitacional, focadas na produção do espaço físico da moradia. No referido programa entende-se que o problema habitacional é bem mais abrangente, e somente o espaço físico da habitação não é suficiente para que as famílias se sustentem no local. Dessa forma, o Programa prevê a implementação concomitante de um projeto habitacional, um projeto de geração de trabalho e renda, e o acompanhamento das famílias nos novos empreendimentos, incluindo apoio ao desenvolvimento comunitário e educação sanitária e ambiental.

Além disso, para atingir os objetivos de reestruturação urbana e recuperação ambiental, estão inclusos também no escopo do Programa um projeto de infraestrutura viária, com a implementação de um sistema de drenagem na zona, e um projeto de valorização paisagística. Ao todo, são cinco projetos que compõem o PIEC:
(a) Projeto de Habitação de Interesse Social;
(b) Projeto de Infraestrutura Viária;
(c) Projeto de Valorização Paisagística;
(d) Projeto de Geração de Trabalho e Renda; e
(e) Projeto de Desenvolvimento Comunitário.

A presente pesquisa dá continuidade ao estudo realizado por Miron (2008), que analisou o processo de desenvolvimento do PIEC e investigou a formação da satisfação e as razões de permanência da população atendida e reassentada nos três empreendimentos habitacionais de interesse social implementados na primeira etapa do referido programa. Uma das principais conclusões desse estudo foi a identificação de problemas na implementação das ações de trabalho social e geração de trabalho e renda, em parte pela dificuldade de implementar as várias ações do Programa de forma sincronizada (MIRON, 2008). Dessa forma, identificou-se a necessidade de analisar em mais profundidade a implementação de projetos nesse contexto, de forma a compreender e analisar o suporte dado pelas práticas gerenciais adotadas. 


\section{Compreendendo a complexidade dos projetos}

A disciplina de gestão de projetos vem sendo alvo de críticas na literatura. Tais críticas focam-se principalmente na falta de suporte que as abordagens de gestão de projetos atuais oferecem para lidar com problemas enfrentados na prática. Segundo Winter et al. (2006), não há um reconhecimento de que projetos estão imersos em um contexto político e social e que são influenciados por esses aspectos. Os mesmos autores apontam que existe um excessivo foco na instrumentalização dos processos, sendo negligenciados a dimensão social da interação entre as pessoas, a dinamicidade dessas relações, os diferentes interesses de agentes que participam do projeto, assim como as pressões políticas e de poder.

Outro problema é a desconsideração de que projetos podem ter naturezas diferentes. Atkinson, Crawford e Ward (2006) enfatizam que compreender a natureza dos projetos é um fator importante para determinar a abordagem de gestão mais apropriada. Os mesmos autores, com base no trabalho de Crawford e Pollack (2004), apresentam dois cenários distintos: em um extremo, uma visão hard (mecanicista e cartesiana), e em outro, uma visão mais soft (holística) (Quadro 1).
Projetos cujas características predominantes estão baseadas em uma visão hard geralmente apresentam um objetivo claro e tangível, sendo alguns implementados internamente, em uma organização, estando pouco suscetíveis a influências externas. Em tais projetos, performance técnica e eficiência são prioridades e, assim, as práticas gerenciais podem focar-se no monitoramento e controle. Por outro lado, projetos com características soft apresentam objetivos muitas vezes intangíveis e vagamente definidos, que são altamente suscetíveis a mudanças externas, além de apresentar uma variedade de soluções possíveis. Geralmente, em tais projetos, muitos agentes intervenientes estão envolvidos e sua gestão requer um grande esforço de discussão e negociação entre eles.

Atkinson, Crawford e Ward (2006) sugerem também que existe uma tendência de realização de projetos dentro de programas, ${ }^{2}$ o que requer a necessidade de criar organizações temporárias e flexíveis para coordenar, dirigir e gerenciar a implementação de um grupo de projetos interdependentes, que objetivam a geração de resultados e benefícios relacionados com os objetivos estratégicos da organização (REISS et al., 2006; BARTLETT, 2006). De acordo com Bartlett (2006), projetos insertos em um programa podem não estar diretamente relacionados, mas juntos contribuem para a obtenção de objetivos estratégicos da organização.

\begin{tabular}{|l|c|c|}
\hline & Características da visão hard & Características da visão soft \\
\hline $\begin{array}{l}\text { Clareza dos } \\
\text { objetivos }\end{array}$ & Objetivos claramente definidos & $\begin{array}{c}\text { Ambiguidade na definição dos } \\
\text { objetivos }\end{array}$ \\
\hline $\begin{array}{l}\text { Tangibilidade dos } \\
\text { objetivos }\end{array}$ & Produto final tangível & Conceito abstrato \\
\hline $\begin{array}{l}\text { Mensuração do } \\
\text { sucesso }\end{array}$ & Mensuração quantitativa & Nensuração qualitativa \\
\hline $\begin{array}{l}\text { Permeabilidade do } \\
\text { projeto }\end{array}$ & $\begin{array}{c}\text { Altamente suscetível a influências a influências } \\
\text { externas }\end{array}$ \\
\hline $\begin{array}{l}\text { Número de soluções } \\
\text { alternativas }\end{array}$ & Refinamento de uma solução única & $\begin{array}{c}\text { Exploração de várias soluções } \\
\text { alternativas }\end{array}$ \\
\hline $\begin{array}{l}\text { Participação e papel } \\
\text { do gestor }\end{array}$ & $\begin{array}{c}\text { Gestor experiente, sem participação } \\
\text { de agentes intervenientes }\end{array}$ & $\begin{array}{c}\text { Gestor facilitador, alta participação de } \\
\text { agentes intervenientes }\end{array}$ \\
\hline $\begin{array}{l}\text { Expectativas dos } \\
\text { agentes } \\
\text { intervenientes }\end{array}$ & $\begin{array}{c}\text { Performance técnica e eficiência } \\
\text { são valorizadas, gestão focada no } \\
\text { monitoramento e controle }\end{array}$ & $\begin{array}{c}\text { Relacionamentos, cultura e significado } \\
\text { são valorizados, gestão focada em } \\
\text { negociação e discussão }\end{array}$ \\
\hline
\end{tabular}

Quadro 1 - Dimensões hard e soft da natureza dos projetos

Fonte: adaptado de Crawford e Pollack (2004).

\footnotetext{
20 termo "programa" é mais utilizado no Reino Unido. Nos EUA, a expressão "portfólio de projetos" é mais utilizada.
} 
Alguns autores abordam essa evolução na natureza dos projetos com base na teoria da complexidade e dedicam-se à compreensão da complexidade inerente aos projetos, em busca de práticas mais adequadas de gestão. Segundo Williams (2002), quanto maior a diferenciação e a interdependência entre as partes que constituem um projeto, mais complexo este é. Quanto maior o número de sistemas e subsistemas de um produto e suas interconexões, maior é o número de impactos cruzados (mudanças em um subsistema que implicam mudanças em outro subsistema) e maior a complexidade do produto (WILLIAMS, 2002). Existem, também, outras duas formas de complexidade, que devem ser levadas em consideração (WILLIAMS, 2002): a multiplicidade de objetivos, e a multiplicidade de agentes intervenientes que participam de um projeto. Muitos projetos possuem objetivos múltiplos e muitas vezes conflitantes. Além disso, há a complexidade relacionada aos agentes, que ocorre de forma similar à relacionada aos objetivos.

Williams (2002) ainda sugere mais uma fonte de complexidade, que é a incerteza. A incerteza está relacionada com a instabilidade das premissas nas quais está baseado o planejamento das atividades (JONES; DECKRO, 1993). Turner e Cochrane (1993) afirmam que duas fontes de incerteza adicionam complexidade aos projetos: a primeira diz respeito ao grau de definição de seus objetivos, e a segunda diz respeito ao grau de definição dos métodos para atingir tais objetivos.

De acordo com Morris e Hough (1987 ${ }^{3}$ apud BACCARINI, 1996), projetos complexos demandam um nível excepcional de gestão, e os sistemas convencionais desenvolvidos para projetos normais têm-se mostrado ineficazes para projetos complexos. Williams (2002) enfatiza que tal complexidade vai de encontro à premissa das tradicionais práticas de gestão, que assumem uma progressão linear ao longo do projeto. Atkinson, Crawford e Ward (2006) adicionam que, tradicionalmente, a gestão de projetos está direcionada para que as equipes realizem as atividades de maneira correta, assumindo que existe uma clara definição do que precisa ser feito. Dessa forma, o foco volta-se para a redução das incertezas e para a obtenção de um objetivo predefinido, deixando-se de lado questões mais estratégicas, como a adequação dos objetivos e a definição de meios adequados para medir performance (ATKINSON; CRAWFORD; WARD, 2006).

\footnotetext{
${ }^{3}$ MORRIS, P. W. G. ; HOUGH G. H. The Anatomy of Majo Projects: a study of the reality of project management. Chichester: J ohn Wiley, 1987.
}

As práticas tradicionais falham em lidar com a complexidade de programas sociais pelas seguintes razões (COMMUNITY..., 2001):

(a) consideram que há uma progressão linear entre as ações planejadas e a obtenção das metas estipuladas nos projetos;

(b) focam-se na verificação de que as ações planejadas estão sendo realizadas, como se bastassem para que os benefícios sejam gerados; e

(c) desconsiderem análises qualitativas do impacto desses programas.

Segundo a Community Development Resource CDRA - (2001), projetos complexos raramente desenvolvem-se de forma previsível e constante, devendo-se considerar a necessidade de adicionais reflexões, julgamentos e decisões ao longo de sua implementação. O mesmo estudo aponta que, apesar do crescente reconhecimento da complexidade de programas comunitários, os métodos comumente utilizados para avaliá-los e monitorá-los são baseados em práticas tradicionais de gestão que trazem uma visão bastante simplificada da realidade (COMMUNITY..., 2006). No referido estudo, sugere-se que as práticas tradicionais devem ser complementadas com avaliações qualitativas, incluindo a realização de entrevistas e um maior contato com a comunidade para qual o programa se destina (COMMUNITY..., 2001).

Grandes projetos urbanos envolvem renovação urbana de áreas ociosas e obsoletas, apresentando elevada complexidade, em função da grande dimensão das intervenções, pela dificuldade de implementação e pelo elevado impacto no entorno urbano (ULTRAMARI; REZENDE, 2007). A escala desses projetos pode variar, podendo envolver uma ampla gama de intervenções, tais como a recuperação de áreas centrais, a valorização de áreas costeiras e ribeirinhas, o resgate de patrimônios arquitetônicos e urbanísticos, e a disponibilização de novas estruturas de lazer e turismo (ULTRAMARI; REZENDE, 2007).

Tais projetos envolvem diversos atores, incluindo o poder público, e requerem, normalmente, muitos recursos financeiros, envolvendo uma composição de investimento bastante complexa, tanto de fontes de recursos nacionais como internacionais (LUNGO, 2002). Caracterizam-se também pela introdução de novos processos urbanos e questionamento do planejamento urbano tradicional, uma vez que esses projetos excedem o escopo das normas e políticas prevalecentes (LUNGO, 2002). Ultramari e Rezende (2007) observam ainda que raramente o custo desses 
projetos corresponde ao planejado, excedendo-se mais do que o dobro na maioria das vezes. Por fim, os referidos autores apontam a necessidade de minimizar os impactos negativos desses projetos, relacionados à desapropriação das áreas destinadas à implementação e à necessidade de realocação de famílias, assim como à valorização imobiliária das áreas, que pode resultar na apropriação majoritária desses benefícios pela iniciativa privada. ${ }^{4}$

\section{Método de pesquisa}

A Figura 1 apresenta a área na qual o PIEC vem sendo implementado. Esse programa iniciou-se em 1999 e vem sendo implantado sob a responsabilidade da Prefeitura Municipal de Porto Alegre. Para sua execução foi criada uma unidade de gestão geral do Programa, que coordena as atividades de cinco unidades executoras, a cargo de diferentes secretarias municipais (Quadro 2).

A estratégia de pesquisa utilizada foi estudo de caso, e a análise do processo de implementação do Programa foi realizada entre março e dezembro de 2008, incluindo a discussão dos resultados com a equipe do Programa. Tal análise focou-se no andamento do Programa e na compreensão dos principais motivos pelos quais os projetos não estavam sendo implementados de forma simultânea. Buscou-se compreender os mecanismos gerenciais utilizados, tais como a organização e a estrutura da equipe envolvida, e as ferramentas e procedimentos de gestão adotados.
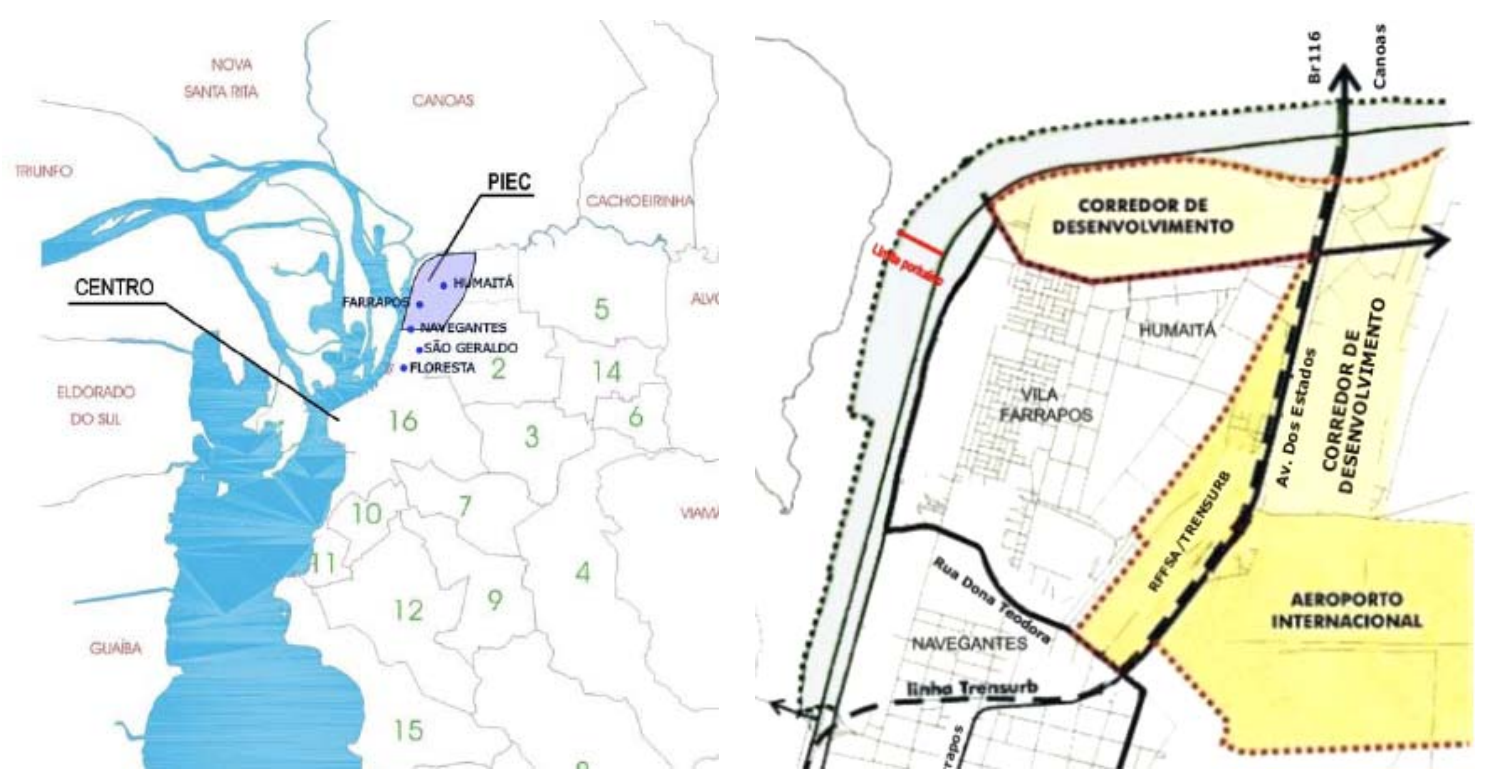

Figura 1 - Área de implementação do PIEC

Fonte: Miron (2008) e adaptado de PMPA (1999).

\begin{tabular}{|l|l|}
\hline \multicolumn{1}{|c|}{ Projeto } & \multicolumn{1}{c|}{ Órgão responsável } \\
\hline Habitação Social & Departamento Municipal de Habitação (Demhab) \\
\hline $\begin{array}{l}\text { Desenvolvimento Comunitário e } \\
\text { Trabalho Social }\end{array}$ & $\begin{array}{l}\text { Demhab. Trabalho social repassado posteriormente para } \\
\text { a Empresa Kepler }\end{array}$ \\
& Centro Administrativo Regional Noroeste (CAR) e \\
& Secretaria Municipal de Coordenação Política e \\
& Governança Local (SMCPGL) \\
\hline Geração de trabalho e renda & Secretaria Municipal de Indústria e Comércio (SMIC) e \\
& Departamento Municipal de Limpeza Urbana (DMLU) \\
\hline Paisagismo & Secretaria Municipal do Meio Ambiente (SMAM) \\
\hline Infraestrutura viária & Secretaria Municipal de Obras e Viação (SMOV) \\
\hline
\end{tabular}

Quadro 2 - Órgãos envolvidos na execução dos cinco projetos que compõem o PIEC

\footnotetext{
${ }^{4}$ Esse fenômeno é denominado de gentrification na literatura e pode levar à expulsão dos moradores de origem (ULTRAMARI; REZENDE, 2007).
} 
Para o desenvolvimento da pesquisa, primeiramente foram definidos dois constructos:

(a) eficiência, relacionada ao tempo gasto nas atividades referentes à implementação das ações e ao montante de recursos financeiros utilizados; e

(b) eficácia, referente ao número de atividades concluídas e às razões pelas quais algumas atividades não foram realizadas dentro do prazo previsto.

Em relação ao planejamento do Programa, o principal instrumento utilizado para análise foi o Marco Lógico do Programa, um instrumento que pode ser utilizado tanto para o planejamento como para o monitoramento de projetos. No Marco Lógico estão descritos os principais objetivos do Programa, assim como os resultados esperados de cada projeto. Esse instrumento também contém informações sobre os principais indicadores que serão utilizados para monitorar o Programa e forma de coleta, assim como pressupostos importantes para a implementação das ações.

Foram utilizadas várias fontes de evidência para a análise do processo de implementação, incluindo entrevistas, análise de documentos e análise de dados disponíveis. Os principais documentos analisados foram:

(a) relatórios para órgãos de fomento, nos quais são descritas as atividades realizadas, custo das obras licitadas, data de conclusão das ações e providências em andamento;

(b) projetos urbanísticos e arquitetônicos;

(c) termos de referência para a contratação da consultoria para as ações sociais; e

(d) relatório sobre cursos realizados.

As entrevistas foram realizadas com representantes das diferentes secretarias responsáveis pela execução dos projetos (Quadro 3), tendo como objetivos entender as relações institucionais envolvidas e complementar as informações obtidas na análise documental. Ao todo, foram realizadas dez entrevistas semiestruturadas, que tiveram duração aproximada de 1h30min. Através do Portal de Gestão da Prefeitura Municipal de Porto Alegre foi possível acompanhar o conjunto das ações correntes do PIEC on-line. O referido portal contém principalmente dados referentes ao avanço físico dos projetos (incluindo indicadores), ao andamento das atividades (concluídas e em andamento) e às dificuldades encontradas para a execução das atividades não concluídas, assim como as alternativas que estão sendo buscadas para sua conclusão.

\section{Processo de implementação do PIEC}

Dado seu longo período de planejamento e implementação, alguns eventos importantes que afetaram o andamento do Programa merecem ser mencionados. Primeiramente, a realização de eleições em 2004 e a consequente mudança de governo municipal resultaram numa série de alterações administrativas no Programa, incluindo a mudança das equipes e a reorganização de responsabilidades. Durante esse período de troca de governo, o Programa sofreu uma readaptação, ocasionando uma redução de velocidade em sua implementação. Outro evento importante que ocorreu nesse período foi a redução da taxa de câmbio do dólar, moeda utilizada para o repasse de verbas do agente financiador, o Fundo Financeiro para o Desenvolvimento da Bacia do Prata (Fonplata). Essa desvalorização resultou na drástica redução da verba solicitada ao agente financeiro. Por conseguinte, várias atividades já planejadas tiveram de ser reavaliadas, assim como a busca por fontes alternativas de recursos teve de ser explorada.

\begin{tabular}{|l|l|}
\hline Relação dos entrevistados & Responsabilidade no PIEC \\
\hline $\begin{array}{l}\text { Arquitetos e Urbanistas do Departamento Municipal } \\
\text { de Habitação (Demhab) }\end{array}$ & Projeto de habitação social \\
\hline $\begin{array}{l}\text { Assistentes Sociais do Departamento Municipal de } \\
\text { Habitação (Demhab) }\end{array}$ & Trabalho social \\
\hline Assistentes Sociais da Empresa Kepler & Execução de atividades do trabalho social \\
\hline Coordenador Geral do Programa (3 entrevistas) & Coordenação geral do Programa \\
\hline $\begin{array}{l}\text { Representante da Secretaria Municipal de Indústria e } \\
\text { Comércio (SMIC) }\end{array}$ & Projeto de geração de trabalho e renda \\
\hline $\begin{array}{l}\text { Representante do Departamento Municipal de } \\
\text { Limpeza Urbana (DMLU) }\end{array}$ & $\begin{array}{l}\text { Ações do projeto de geração de trabalho e renda que } \\
\text { dizem respeito à coleta seletiva de lixo }\end{array}$ \\
\hline $\begin{array}{l}\text { Representante da Secretaria Municipal do Meio } \\
\text { Ambiente (SMAM) }\end{array}$ & Projeto de valorização paisagística \\
\hline $\begin{array}{l}\text { Representantes da Secretaria Municipal de Obras e } \\
\text { Viação (SMOV) }\end{array}$ & Projeto de infraestrutura viária \\
\hline
\end{tabular}

Quadro 3 - Relação de entrevistas realizadas

78 Tillmann, P. A.; Scussel, M. C. B.; Formoso, C. T.; Miron, L. I. G. 
Dessa forma, cabe destacar que as atividades referentes ao planejamento do Programa foram executadas predominantemente no governo anterior ao de 2005, enquanto as atividades de implementação física concentraram-se sob a responsabilidade de uma nova gestão, que assumiu o Programa a partir de 2005.

\section{Abordagens utilizadas para a gestão do programa}

O Marco Lógico é uma abordagem comumente utilizada em programas sociais, sendo exigido com frequência por agências de fomento (EUROPEAN..., 2002; GRANT, 2007). No caso do PIEC, sua implementação foi demandada pelo Fonplata. O instrumento central do Marco Lógico é uma matriz que busca facilitar a visualização da relação entre as ações planejadas, o resultado dessas ações e a obtenção dos objetivos mais estratégicos (GRANT, 2007). Segundo o mesmo autor, tal matriz prevê também a designação de um sistema de indicadores para esses diferentes níveis, possibilitando o monitoramento do programa tanto em nível operacional quanto estratégico. Esse instrumento também estimula a previsão dos meios de verificação e os pressupostos para a obtenção dos objetivos esperados (GRANT, 2007). A Figura 2, baseada no Marco Lógico do PIEC, ilustra a relação entre os resultados esperados de cada projeto e os objetivos mais estratégicos do Programa.

A utilização do Marco Lógico no Programa evidenciou uma preocupação em planejar adequadamente o escopo dos diferentes projetos para que os objetivos mais estratégicos fossem alcançados. Entretanto, identificou-se uma dificuldade de preencher os indicadores de performance, uma vez que os indicadores previstos são predominantemente associados aos projetos mais tangíveis e fáceis de ser mensurados, além de indicadores para os objetivos estratégicos não terem sido definidos. Também houve dificuldade de estabelecer os meios de mensuração desses indicadores, sendo os relatórios periódicos o principal meio de verificação para os indicadores. Ademais, os pressupostos estabelecidos para a implementação do Programa diziam respeito somente à disponibilidade das terras, não havendo uma análise de como lidar com tais pressupostos.

\begin{tabular}{|c|c|c|c|c|c|}
\hline & \multicolumn{5}{|c|}{ PROGRAMA INTEGRADO ENTRADA DA CIDADE (PIEC) } \\
\hline & \multicolumn{5}{|c|}{ OBJETIVO SUPERIOR DO PROGRAMA } \\
\hline & \multicolumn{5}{|c|}{ Melhoria da qualidade de vida.da população (bairros Humaitá, Navegantes e Farrapos) } \\
\hline & Projeto de HIS & $\begin{array}{l}\text { Projeto de infra- } \\
\text { estrutura viaria }\end{array}$ & $\begin{array}{c}\text { Projeto de valorizaçăo } \\
\text { paisagistica }\end{array}$ & $\begin{array}{l}\text { Projeto de geraçâ de } \\
\text { trabalho e renda }\end{array}$ & $\begin{array}{l}\text { Projeto de Desenvolvimento } \\
\text { Comunitário }\end{array}$ \\
\hline & \multicolumn{5}{|c|}{ OBJETIVO SUPERIOR DOS PROJETOS } \\
\hline & \multicolumn{5}{|c|}{ Estruturação urbana e recuperação ambiental da Zona Norte de Porto Alegre } \\
\hline 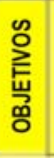 & $\begin{array}{l}\text { Melhoria das } \\
\text { condiçøes de } \\
\text { habitabilidade da } \\
\text { populaçắo. }\end{array}$ & $\begin{array}{l}\text { Estruturaçăo da malha } \\
\text { viária dos bairros. }\end{array}$ & $\begin{array}{c}\text { Valorizaçăo paisagistica } \\
\text { dos beimos. }\end{array}$ & $\begin{array}{l}\text { Promoçalo de } \\
\text { altemativas de } \\
\text { Geraça de Trabalho } \\
\text { e Renda (GTR) para a } \\
\text { populaçào. }\end{array}$ & $\begin{array}{l}\text { Apoio ao desenvolvimento } \\
\text { comunitário da populaçào. }\end{array}$ \\
\hline \multirow{5}{*}{ 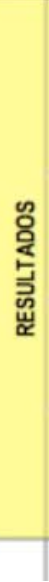 } & $\begin{array}{l}\text { 1. Áreas para a } \\
\text { implantaçăo dos } \\
\text { projetos de HIS e } \\
\text { Geraçăo de Trabalho } \\
\text { e Renda. }\end{array}$ & $\begin{array}{l}\text { 1. Estudos de circulaçăo } \\
\text { viảria. }\end{array}$ & $\begin{array}{l}\text { 1. Recuperaçào, } \\
\text { melhoria e manutençăo } \\
\text { de âreas de lazer } \\
\text { existentes }\end{array}$ & $\begin{array}{l}\text { 1. Duas unidades de } \\
\text { tragem de residuos } \\
\text { sollidos. }\end{array}$ & $\begin{array}{l}\text { 1. Mobilizaçbo e Organizaçào } \\
\text { Comunitaria (MOC). }\end{array}$ \\
\hline & $\begin{array}{l}\text { 2. Intervençles } \\
\text { habitacionais e de } \\
\text { servicos publicos de } \\
\text { saúde e educaçato. }\end{array}$ & $\begin{array}{l}\text { 2. Áreas para } \\
\text { implantaçăo do Projeto } \\
\text { de Infra-Estrutura Viária } \\
\text { d'sponibilizadas }\end{array}$ & $\begin{array}{l}\text { 2. Tratamento } \\
\text { paisagistico de novas } \\
\text { âreas verdes. }\end{array}$ & $\begin{array}{l}\text { 2. Centro de Apoio ao } \\
\text { Desenvolvimento } \\
\text { Económico Regional. }\end{array}$ & 2. Acbes de Politicas Sociais. \\
\hline & \multirow[t]{2}{*}{$\begin{array}{l}\text { 3. Instalaçăo das } \\
\text { familias em unidades } \\
\text { habitacionais. }\end{array}$} & $\begin{array}{l}\text { 3. Obras de intra- } \\
\text { estrutura váría. }\end{array}$ & & $\begin{array}{l}\text { 3. Cooperativa de } \\
\text { Produçăo e Servicos } \\
\text { - CONSTRUSOL. }\end{array}$ & \\
\hline & & $\begin{array}{l}\text { 4. Obras de } \\
\text { recuperaç̧̌o do sistema } \\
\text { de drenagem e proteçào } \\
\text { contra as cheias. }\end{array}$ & & & \\
\hline & ATIVIDADES & ATIVIDADES & ATIVIDADES & ATIVIDADES & ATIVIDADES \\
\hline
\end{tabular}

Figura 2 - Relação entre nível operacional e estratégico do PIEC

Fonte: Formoso e Miron (2008). 
A fim de operacionalizar a gestão do Programa, foi criada a Unidade Executora do Programa (UEP), com finalidade de coordenar, gerenciar $\mathrm{e}$ supervisionar o Programa. Ficou a seu encargo também a interlocução com os agentes financeiros e a articulação entre as Unidades Executoras Locais (UEL), que foram criadas nas secretarias diretamente envolvidas com os projetos do PIEC. Cada UEL é responsável pela execução de um projeto específico, envolvendo desde o processo licitatório até o acompanhamento e fiscalização de sua execução. Essa atividade de fiscalização é supervisionada pela UEP.

As UELs prestam contas à UEP, que por sua vez presta contas ao agente financeiro por meio de relatórios periódicos. Tais relatórios contêm informações sobre o andamento do projeto, os gastos despendidos, os entraves encontrados e a maneira como estão sendo solucionados. Observou-se que não há uma comparação das atividades já executadas com o plano inicial. Tal fato dá-se principalmente pelo elevado grau de mudanças realizadas durante a implementação do Programa. A periódica adição de novos recursos financeiros, a extensão de prazos e a mudança de escopo dos projetos dificultam a atualização dos planos e, por conseguinte, a comparação entre o que foi realizado e o que foi planejado.

As UELs e a UEP reuniam-se periodicamente para discutir o andamento das atividades e solucionar eventuais entraves para sua execução. Identificouse, entretanto, uma burocratização desse processo. Mudanças nos projetos, seja pela inviabilidade de execução ou pela necessidade de solucionar entraves para a execução, deviam ser documentadas e aprovadas pelo coordenador do Programa, e muitas vezes também por outros departamentos da Prefeitura Municipal.

Constatou-se que os mecanismos de gestão utilizados priorizavam a gestão individual dos projetos. Os projetos eram discutidos e monitorados de forma individualizada, apresentando também processos de implementação distintos. O projeto habitacional era planejado e detalhado pelo Demhab ${ }^{5}$ e executado por uma empresa construtora através de licitação, encarregando-se o Demhab da fiscalização da obra. O projeto paisagístico seguia um caminho semelhante ao do projeto habitacional. Já no caso do projeto de infraestrutura viária, as fases de desenho e detalhamento, assim como a execução da obra eram todas licitadas, sendo a SMOV responsável pela fiscalização. O acompanhamento das famílias por meio do projeto social começou a ser desenvolvido por uma equipe técnica do Demhab. Entretanto, após a troca de gestão, passou a ser executado por uma empresa licitada. E, por fim, o projeto de geração de trabalho e renda era formado por ações relacionadas à construção de unidades de triagem de lixo, gerenciadas pelo SMMIC e DMLU, e uma série de cursos profissionalizantes, viabilizados mediante convênios como o Serviço Nacional de Aprendizagem do Transporte (Senat) e o Projeto Casa Brasil, do Ministério de Ciência e Tecnologia, que atua em áreas de baixo índice de desenvolvimento.

O portal de gestão on-line também foi criado para auxiliar a gestão do Programa. Seu papel foi permitir que a população tivesse acesso às informações sobre o Programa. Para o desenvolvimento desse portal, foram estabelecidos indicadores que auxiliam a visualização do andamento do Programa. Entretanto, salienta-se que, como no Marco Lógico, os indicadores estipulados eram relativos somente ao avanço físico das obras, além de não haver uma visualização da inter-relação entre o andamento de diferentes projetos.

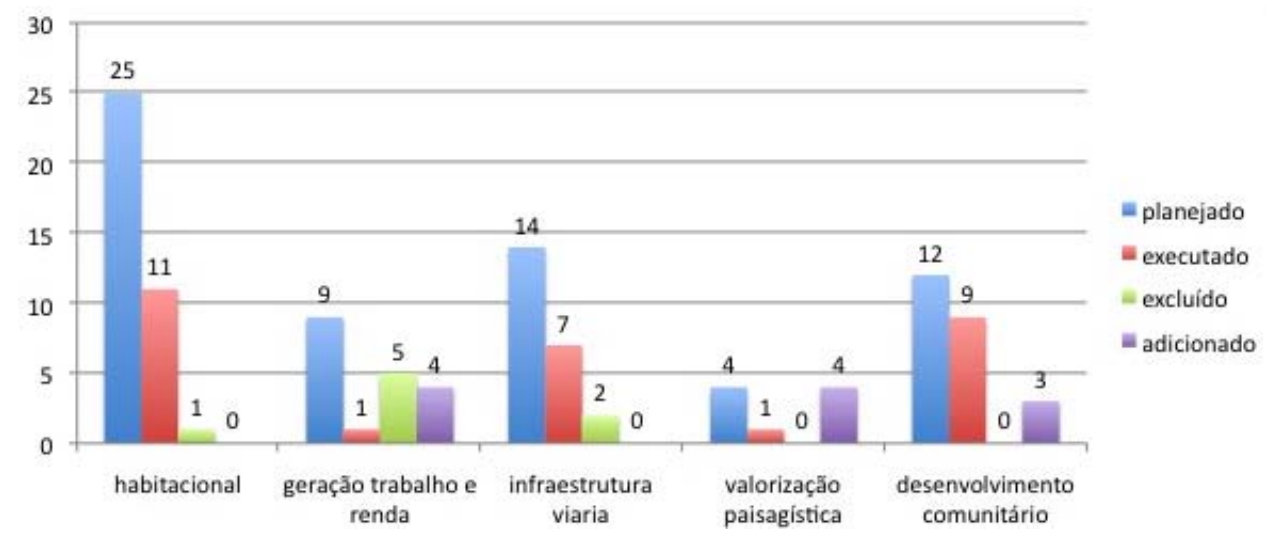

Figura 3 - Status das tarefas planejadas no segundo semestre de 2008

\footnotetext{
${ }^{5} \mathrm{O}$ nome por extenso das secretarias é apresentado na Figura 4.
} 


\section{Análise do avanço físico do Programa}

A Figura 3 apresenta uma síntese do status das atividades planejadas para cada um dos projetos que compõem o Programa, no segundo semestre de 2008. Já a Figura 4 apresenta uma linha do tempo com as atividades referentes a cada projeto, que foram executadas até o primeiro trimestre de 2008.

Pode-se notar que em todos os projetos existem atividades não realizadas, embora o prazo inicial previsto para sua conclusão fosse dezembro de 2008. Observa-se também que, na maioria dos projetos, atividades foram suprimidas e outras adicionadas ao contrato inicial.

Com relação ao Projeto Habitacional, constata-se que, das 25 atividades planejadas (referentes à construção dos empreendimentos), 11 foram executadas. Observa-se, também, a exclusão de um empreendimento devido à área disponível para sua implantação ter sido invadida por uma população a qual não havia sido contabilizada como parte da demanda. O custo para a inclusão dessa demanda tornou inviável a implantação dele. Segundo o coordenador do Programa, uma divulgação precoce do empreendimento ocasionou a referida invasão.

O Projeto de Geração de Trabalho e Renda sofreu alterações substanciais devido ao fato de que algumas atividades foram consideradas inviáveis ao longo da implementação. Das nove atividades planejadas, apenas uma foi executada, cinco tornaram-se inviáveis e quatro foram adicionadas para tentar suprir a demanda não atendida pelas atividades suprimidas. Com relação às três unidades de triagem previstas, somente uma foi implantada até o final da avaliação. O espaço físico para o Centro de Apoio ao Desenvolvimento Econômico Regional (CRD), assim como o que seria destinado à Cooperativa de Produção e Serviços (Construsol), inviabilizados por razões técnicas e financeiras, foram suprimidos. Surgiram novas atividades extracontratuais, como a construção de novas unidades de triagem e a realização de novos convênios para os cursos profissionalizantes. A implementação desse projeto deu-se principalmente a partir da metade de 2007, de forma tardia, pois durante um longo período atividades foram executadas visando à implementação das ações que, ao final, foram suprimidas.

Com relação ao Projeto de Infraestrutura Viária, observa-se que, das 14 atividades planejadas, sete foram concluídas. Além disso, dois itens foram suprimidos devido à priorização de outros projetos e deslocamento dos recursos destinados. Pode-se observar um longo período de planejamento e execução dessas obras. Nas obras do viaduto e duplicação da Dona Teodora, por exemplo, as atividades de estudo e preparação para a intervenção levaram aproximadamente dois anos para ser concluídas, enquanto a execução, ainda não finalizada, começou no segundo trimestre de 2006. Grande parte dessas ações depende de um longo período de estudos, readequações e tramitações legais que antecedem a intervenção física. Readequações foram necessárias devido a erros de projeto de empresas licitadas, o que levou a equipe do PIEC a readequar o projeto para a execução.

Das ações referentes ao Projeto de Valorização Paisagística, somente uma atividade das quatro planejadas foi executada. As atividades inicialmente planejadas para esse projeto ainda estavam em fase de estudos e tramitações, sendo o avanço físico propriamente dito representado apenas pela aquisição de equipamentos. Entretanto, outras atividades foram adicionadas ao escopo do projeto. Tal mudança de escopo está relacionada com a adição ou exclusão de atividades em outros projetos, como o tratamento paisagístico de áreas reservadas para equipamentos que foram inviabilizados. Uma das atividades adicionadas foi a implantação de um jardim linear ao longo da Rua Voluntários da Pátria. No entanto, o andamento dessa obra depende tanto da liberação da área, que se encontra irregularmente ocupada, como de uma negociação com a Concessionária da Rodovia Osório-Porto Alegre (Concepa), que fez algumas exigências no projeto. A equipe também realizou o tratamento do Sítio Laçador e o tratamento das praças de todos os loteamentos implementados até então.

No tocante às atividades relacionadas à mobilização comunitária, elas foram realizadas desde a primeira etapa de implementação dos loteamentos (loteamentos 1, 2 e 3, em 2002 e 2003), dando-se continuidade, na segunda etapa (2004 a 2008), mediante a contratação da empresa Kepler. Segundo entrevista realizada, o principal entrave para o andamento dessa ação é o atraso no pagamento das atividades exercidas. Com relação às políticas sociais, as atividades começaram a ser realizadas somente na segunda etapa da implementação do Programa. Contatou-se que grande parte das atividades previstas e ainda não realizadas dependia da reforma do prédio do Serviço Social da Indústria (Sesi), inviabilizada financeiramente.

A partir das dificuldades descritas acima, foram identificados os principais entraves para a implementação do Programa, assim como suas causas e impactos (Quadro 4). As dificuldades 
enfrentadas na implementação das ações tiveram diferentes causas, as quais podem ser classificadas em categorias:

(a) dificuldades inerentes à incerteza envolvida em um Programa dessa natureza;

(b) dificuldades relacionadas ao contexto de um projeto de iniciativa pública;

(c) dificuldades decorrentes de um planejamento baseado em premissas não verdadeiras; e

(d) dificuldades relacionadas ao baixo suporte oferecido pelos mecanismos de gestão tradicionalmente utilizados nesse contexto.

\section{Discussão}

Conforme observado por Atkinson, Crawford e Ward (2006), alguns projetos possuem elevada complexidade e necessitam de práticas gerenciais alternativas. A complexidade do PIEC caracterizase principalmente pelo elevado grau de interdependência entre os diferentes projetos e ações para atingir os objetivos esperados. Tal complexidade agrava-se ainda pelo grande impacto no entorno urbano e pela necessidade de readequar o escopo de intervenção ao longo de sua implementação. Ainda, o PIEC não visa gerar um produto físico bem definido, mas uma mudança em um contexto urbano e a melhoria da qualidade de vida de uma população, o que requer um conjunto interdependente de ações e espaços físicos. Não há uma solução única, mas sim uma série de soluções possíveis.

Outra característica que aumenta a complexidade do PIEC está relacionada com o contexto de um projeto de iniciativa pública. Existe uma elevada interdependência entre diferentes agentes da Prefeitura, empresas licitadas e outros agentes externos para a implementação de ações. Existe também uma elevada burocratização dos processos necessários para a integração do trabalho dessas equipes. Outro fator observado, apontado por Winter et al. (2006) como uma característica típica de projetos complexos, é a alta suscetibilidade a influências econômicas, políticas e sociais que existem no contexto de iniciativa pública.

Também são identificadas características típicas de projetos de construção, que contribuem para o aumento da complexidade. Tais características dizem respeito à vinculação do projeto a um local específico e consequente necessidade de lidar com aspectos que dificultam a implementação dos projetos: como a disponibilidade de áreas, leis que regulam o uso do espaço urbano e a necessidade de adequação com um espaço preexistente (e.g. conexões viárias).

A elevada complexidade do PIEC indica a necessidade de um sistema de gestão capaz de lidar com tais características. Entretanto, os mecanismos de gestão adotados no Programa estão ainda baseados em um modelo tradicional de gestão, não oferecendo suporte adequado para lidar com a complexidade (WILLIAMS, 2002). Algumas medidas foram tomadas com relação à necessidade de coordenar o PIEC de forma integrada (Quadro 5). Entretanto, tais medidas estão baseadas em pressupostos de uma visão mecanicista.

Apesar da utilização do Marco Lógico, que auxilia o alinhamento estratégico, esse instrumento ofereceu pouco suporte para lidar com as situações emergentes e a necessidade de adaptações. O Programa sofreu uma série de mudanças em seu escopo. Tais mudanças foram realizadas ao longo da implementação, tornando o conteúdo da matriz do Marco Lógico desatualizado e dificultando o monitoramento das ações em relação a seu planejamento. Apesar de o Marco Lógico prever a geração de indicadores, observa-se uma dificuldade de estabelecer indicadores para as ações menos tangíveis, de estipular as formas de mensuração e lidar com pressupostos não verdadeiros para a implementação.

De acordo com a classificação de Crawford e Pollack (2004), a gestão de projetos complexos deveria focar na necessidade de discussão e negociação, em vez de no monitoramento e controle. Entretanto, observou-se no PIEC uma ênfase na estipulação de indicadores e na prestação de contas para com o agente financeiro e a população. Apesar de a prestação de contas ser um fator fundamental em projetos do setor público, os instrumentos gerenciais devem, principalmente, oferecer o adequado suporte para lidar com a complexidade desse contexto.

Ademais, apesar da instituição de uma unidade geral de gestão para facilitar a articulação entre as unidades executoras, a estrutura organizacional do Programa, na qual cada unidade executora é formada dentro de uma secretaria específica da Prefeitura, dificulta a discussão e negociação de aspectos relativos ao Programa em equipe. $\mathrm{O}$ fato de cada projeto adotar um processo diferenciado de planejamento e execução também agrava o grau de diferenciação entre eles. Considerando-se que tais projetos são interdependentes e precisam ser implementados simultaneamente para o sucesso do Programa, essa diferenciação adiciona complexidade e dificulta a integração das ações. 


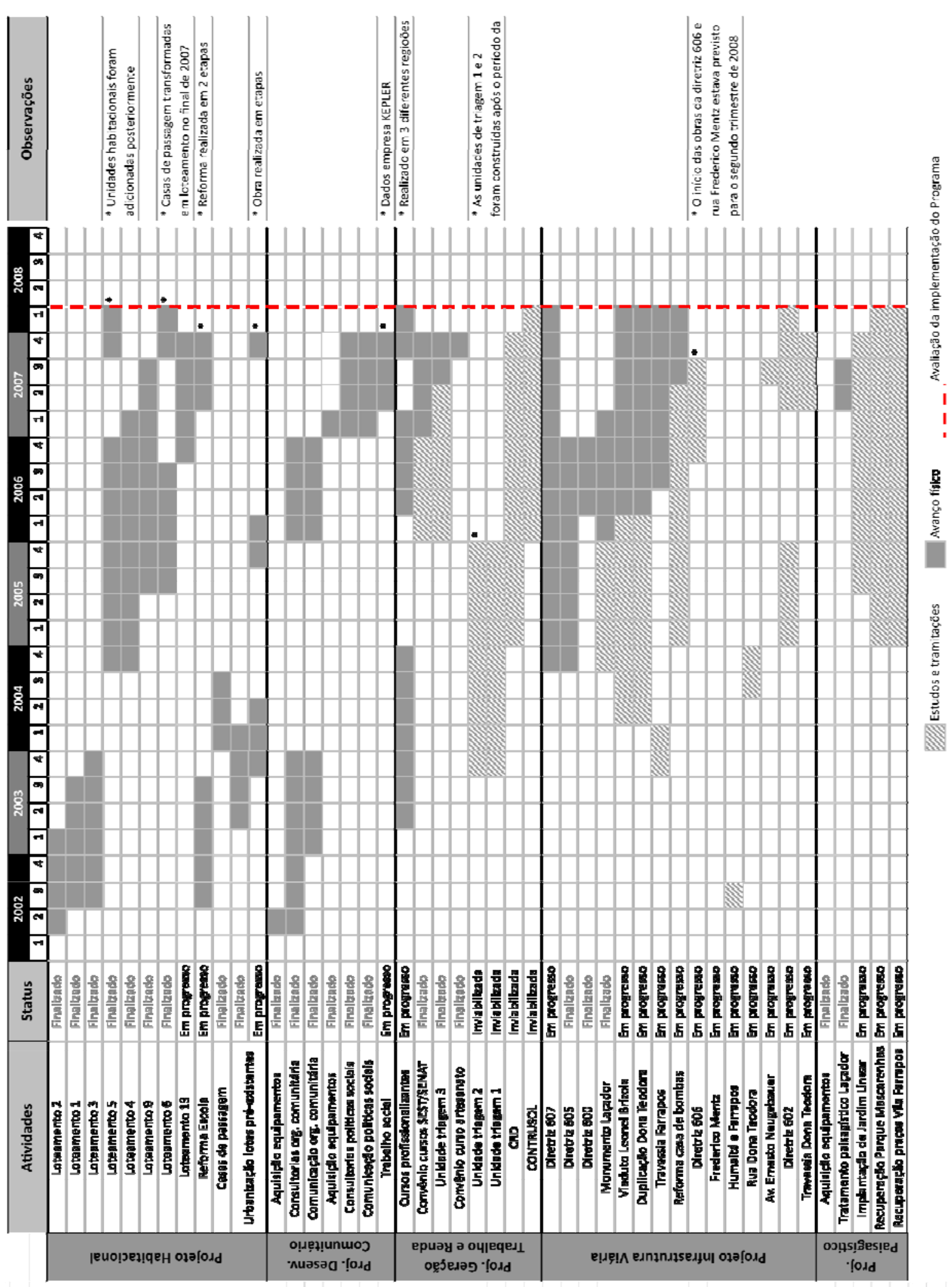

Figura 4 - Andamento físico dos projetos até o primeiro trimestre de 2008 


\begin{tabular}{|c|c|c|}
\hline Causas & Dificuldades & Impacto no processo \\
\hline $\begin{array}{l}\text { Eleições e troca } \\
\text { de governo } \\
\text { (suscetibilidade } \\
\text { a fatores } \\
\text { políticos) }\end{array}$ & $\begin{array}{l}\text { Readequação das metas com base no que a nova equipe entendia como } \\
\text { prioritário; e } \\
\text { readequação dos meios para atingir objetivos com base no entendimento da } \\
\text { nova equipe (terceirizar o serviço social, terceirizar o detalhamento de } \\
\text { projetos, envolver o DMLU em atividades de coleta/seleção de lixo) }\end{array}$ & $\begin{array}{l}\text { Mudanças no escopo dos } \\
\text { projetos, mudanças na } \\
\text { organização da equipe }\end{array}$ \\
\hline $\begin{array}{l}\text { Incerteza com } \\
\text { relação à } \\
\text { viabilidade } \\
\text { técnica de ações } \\
\text { planejadas }\end{array}$ & $\begin{array}{l}\text { Necessidade de reavaliar as ações planejadas, como o caso da Construsol; } \\
\text { dificuldade de mobilizar a população a participar dos cursos } \\
\text { profissionalizantes (quando não há auxílio financeiro); } \\
\text { dificuldade de mobilizar a população para a formalização de associações, } \\
\text { pré-requisitos para trabalhar nas unidades de triagem; e } \\
\text { necessidade de ir em busca de novas alternativas (e.g. empresas parceiras) } \\
\text { para a geração de trabalho e renda }\end{array}$ & $\begin{array}{l}\text { Mudanças no escopo dos } \\
\text { projetos e dificuldade de } \\
\text { disponibilizar } \\
\text { simultaneamente o espaço } \\
\text { da habitação e } \\
\text { oportunidades de emprego } \\
\text { e renda }\end{array}$ \\
\hline $\begin{array}{l}\text { Natureza do } \\
\text { Programa e } \\
\text { incerteza }\end{array}$ & $\begin{array}{l}\text { Demora para a posse legal das terras. Período prolongado, ainda mais no } \\
\text { caso da presença de famílias morando ilegalmente nas áreas; e } \\
\text { invasão de área destinada a um projeto habitacional devido a uma precoce } \\
\text { divulgação do empreendimento }\end{array}$ & $\begin{array}{l}\text { Atraso e inviabilidade de } \\
\text { implementação de um } \\
\text { empreendimento } \\
\text { planejado }\end{array}$ \\
\hline $\begin{array}{l}\text { Problemas } \\
\text { relacionados } \\
\text { com a licitação } \\
\text { de serviços }\end{array}$ & $\begin{array}{l}\text { Problemas financeiros nas empresas licitadas, no decorrer da execução dos } \\
\text { serviços contratados; } \\
\text { revisão dos projetos entregues por empresas licitadas devido à inviabilidade } \\
\text { de execução deles; } \\
\text { revisão dos projetos terceirizados entregues devido à não adequação à } \\
\text { legislação local (e.g. altura incompatível do viaduto em relação ao } \\
\text { aeroporto próximo à zona); } \\
\text { demora dos processos licitatórios devido ao não cumprimento de editais, } \\
\text { não candidatura ou erros nas propostas das empresas; e } \\
\text { atraso no pagamento de empresas terceirizadas }\end{array}$ & $\begin{array}{l}\text { Retrabalho e atraso na } \\
\text { implementação de ações } \\
\text { propostas }\end{array}$ \\
\hline $\begin{array}{l}\text { Estrutura } \\
\text { organizacional } \\
\text { do Programa e } \\
\text { burocratização } \\
\text { dos processos }\end{array}$ & $\begin{array}{l}\text { Dependência de agentes externos para a solução de problemas na execução } \\
\text { de tarefas e excessiva burocratização e demora desse processo; } \\
\text { dependência da aprovação de outros departamentos da Prefeitura ou } \\
\text { agentes externos (e.g. Concepa) para a execução de tarefas; excessiva } \\
\text { burocratização e demora desse processo; e } \\
\text { dificuldade de mobilizar a equipe técnica da Prefeitura quando há um pico } \\
\text { de demanda nos projetos específicos do Programa }\end{array}$ & $\begin{array}{l}\text { Elevado grau de } \\
\text { interdependência entre } \\
\text { diferentes equipes, } \\
\text { dificuldade de } \\
\text { colaboração e longos } \\
\text { períodos de espera }\end{array}$ \\
\hline $\begin{array}{l}\text { Gestão } \\
\text { priorizando os } \\
\text { projetos } \\
\text { individuais e } \\
\text { enfatizando } \\
\text { monitoramento e } \\
\text { controle }\end{array}$ & $\begin{array}{l}\text { Cada projeto apresenta um processo de implementação diferenciado com } \\
\text { relação ao grau de terceirização das atividades; } \\
\text { monitoramento focado no andamento individual dos projetos; e } \\
\text { mensuração focada no avanço físico com indicadores estipulados somente } \\
\text { para os projetos mais tangíveis }\end{array}$ & $\begin{array}{l}\text { Elevado grau de } \\
\text { diferenciação na execução } \\
\text { de cada projeto; } \\
\text { dificuldade de visualizar a } \\
\text { sincronização entre as } \\
\text { ações }\end{array}$ \\
\hline
\end{tabular}

\section{Quadro 4 - Principais entraves encontrados para a implementação sincronizada dos projetos}




\begin{tabular}{|l|l|l|}
\hline \multicolumn{1}{|c|}{ Medidas gerenciais } & $\begin{array}{l}\text { Pressupostos baseados em uma visão } \\
\text { mecanicista }\end{array}$ & \multicolumn{1}{|c|}{ Dificuldades enfrentadas } \\
\hline $\begin{array}{l}\text { Utilização do Marco Lógico - } \\
\text { visualização de como cada } \\
\text { projeto irá contribuir para o } \\
\text { objetivo geral, estabelece bases } \\
\text { para o monitoramento e } \\
\begin{array}{l}\text { acompanhamento da obtenção } \\
\text { de resultados e identifica } \\
\text { premissas para a implementação }\end{array}\end{array}$ & $\begin{array}{l}\text { Todos os resultados podem ser } \\
\text { quantificados e transformados em } \\
\text { indicadores; } \\
\text { todos os indicadores podem ser } \\
\text { facilmente observados e coletados } \\
\text { durante a implementação do Programa; } \\
\text { as premissas para a implementação são } \\
\text { sempre verdadeiras; } \\
\text { os planos não mudam }\end{array}$ & $\begin{array}{l}\text { dificuldade de estabelecer } \\
\text { projetos menos tangíveis; } \\
\text { dificuldade de monitorar a obtenção } \\
\text { de objetivos mais estratégicos }\end{array}$ \\
\hline $\begin{array}{l}\text { Delegação da responsabilidade } \\
\text { dos projetos a secretarias } \\
\text { específicas; } \\
\text { reuniões periódicas para } \\
\text { discussão do andamento de cada } \\
\text { projeto e solução de entraves }\end{array}$ & $\begin{array}{l}\text { Trabalho pode ser dividido por } \\
\text { especialidade (estrutura departamental) } \\
\text { sem considerar interação; } \\
\text { o todo pode ser quebrado em partes para } \\
\text { facilitar a gestão }\end{array}$ & $\begin{array}{l}\text { implementá-los; } \\
\text { excessiva burocratização entre } \\
\text { equipes dos projetos e coordenador } \\
\text { geral e entre equipes dos projetos e } \\
\text { outros departamentos da Prefeitura }\end{array}$ \\
\hline $\begin{array}{l}\text { Planejamento pelo setor público } \\
\text { e contratação dos serviços }\end{array}$ & $\begin{array}{l}\text { Os planos não mudam; } \\
\text { as atividades de planejamento e } \\
\text { execução podem ser sequenciais sem } \\
\text { considerar iteração }\end{array}$ & $\begin{array}{l}\text { Baixa qualidade dos serviços } \\
\text { entregues; } \\
\text { retrabalho }\end{array}$ \\
\hline
\end{tabular}

Quadro 5 - Medidas gerenciais e dificuldades enfrentadas

Além disso, os mandatórios processos licitatórios utilizados nesse contexto partem de um pressuposto de estabilidade e desconsideram a necessidade de interação entre planejamento e execução. Tais processos são ainda muitas vezes demorados e geram retrabalho por assumirem que os serviços serão entregues sem a necessidade de readaptações.

A literatura sugere práticas gerenciais alternativas que poderiam ser adotadas nesse caso. Tais práticas devem enfatizar aspectos como a discussão e negociação entre os agentes intervenientes (ATKINSON; CRAWFORD; WARD, 2006) e a introdução de mecanismos que facilitam a colaboração entre equipes, a necessidade de coordenar as atividades para que, em conjunto, gerem as capacidades necessárias para que objetivos estratégicos sejam atingidos (BARLETT, 2006), a definição de meios adequados para compreender se esses objetivos estão mesmo sendo atingidos (ATKINSON; CRAWFORD; WARD, 2006) e a introdução de meios de avaliação mais qualitativos, que enfatizem a aprendizagem em equipe, e não somente o controle. Uma abordagem colaborativa e com ênfase na aprendizagem poderia contribuir para melhor lidar com as diferentes situações emergentes ao longo do projeto. O trabalho em equipe pode também contribuir para que os pressupostos para a implementação de programas desse tipo sejam mais bem pensados, assim como a necessidade de medidas alternativas, caso tais pressupostos não sejam verdadeiros. A troca de conhecimento entre os diferentes participantes de um projeto dessa grandeza poderia contribuir para que tais premissas sejam mais bem formuladas, monitoradas e ajustadas. Assim, a suscetibilidade às influências externas, assim como as situações emergentes devem ser propriamente reconhecidas e gerenciadas.

Entretanto, existem barreiras para a adoção de práticas de gestão mais adequadas à complexidade do contexto. Tais barreiras dizem respeito ao contexto no qual esses projetos estão insertos. Projetos urbanos de iniciativa pública no Brasil estão sujeitos a uma série de características, como a elevada burocratização dos processos, a estrutura organizacional dos órgãos públicos, aos procedimentos mandatórios para a implementação das ações, à elevada suscetibilidade a fatores políticos e econômicos, entre outros. Esse conjunto de características inibe a adoção de mecanismos gerenciais mais adequados. Aspectos como a colaboração, a aprendizagem entre equipes e a resolução de problemas em conjunto, que poderiam melhorar a qualidade das soluções desenvolvidas, demandam a remoção de uma série de barreiras inerentes relacionadas ao contexto de contratação e acompanhamento de obras públicas no Brasil. 


\section{Conclusões}

O presente artigo teve por objetivo propor melhorias no processo de gestão de projetos complexos através da análise das dificuldades de gerir um projeto urbano com elevada complexidade, apontando as deficiências das abordagens de gestão que são tradicionalmente utilizadas nesse contexto. Para tanto, realizou-se um estudo de caso no Programa Integrado Entrada da Cidade, em Porto Alegre. O estudo descreve os principais aspectos que caracterizam a complexidade desses projetos e aponta o insuficiente suporte oferecido pelo tradicional modelo de gestão adotado nesse contexto. Tal modelo baseia-se em uma visão mecanicista, enquanto para lidar com tal contexto faz-se necessária a consideração de uma perspectiva mais holística de gestão, capaz de lidar com um elevado grau de interdependência entre ações, alta suscetibilidade a fatores externos e com uma série de situações que emergem ao longo da implementação desses projetos.

Além disso, a análise da gestão do PIEC permitiu a constatação de que a gestão desses projetos não se dá de forma consolidada. Existe um modelo gerencial que é seguido; entretanto, a adoção de técnicas e ferramentas de gestão é superficial e pouco eficaz. Existe uma grande barreira para a melhoria da gestão desses projetos relacionada com o contexto de construção por iniciativa pública no Brasil. Tais barreiras são referentes a procedimentos mandatórios, que inibem a adoção de maneiras mais adequadas de organização do trabalho.

Este estudo ilustrou o potencial dos mecanismos gerenciais em contribuir para a melhoria da implementação de projetos urbanos com elevada complexidade. Salienta-se que, na literatura de projetos e planejamento urbano, pouco se discute o papel dos mecanismos de gestão no sucesso da implementação desses projetos. Dessa forma, para futuros estudos sugere-se a análise de abordagens gerenciais mais adequadas para esse contexto de alta complexidade, que sejam baseadas em uma visão mais holística de gestão de projetos. Tais abordagens, sugeridas em uma literatura ainda emergente das críticas às tradicionais formas de gestão, devem ter seus princípios explicitados e testados na prática gerencial de projetos complexos. Formas alternativas de organização do trabalho devem ser exploradas, assim como instrumentos mais flexíveis de gestão, que possam lidar melhor com situações emergentes e com a necessidade de uma visualização mais sistêmica desses projetos. Paralelamente, melhores maneiras de lidar com os entraves do contexto da construção por iniciativa pública no Brasil devem ser analisadas.

\section{Referências}

ATKINSON, R.; CRAWFORD, L.; WARD, S. Fundamental Uncertainties in Projects and the Scope of Project Management. International Journal of Project Management, v. 24, n. 8, p. 687-698, nov. 2006.

BACCARINI, D. The Concept of Project Complexity: a review. International Journal of Project Management, v. 14, n. 4, p. 201-204, 1996.

BARTLETT, J. Managing Programmes of Business Change. 4. ed. Hampshire, UK: Project Manager Today, 2006.

\section{COMMUNITY DEVELOPMENT RESOURCE} ASSOCIATION. Measuring Development: holding infinity. 2001. Cape Town: Community Development Resource Association, 2001. Annual Report 2000/2001. Disponível em:

$<$ http://www.cdra.org.za/index.php?option=com_c ontent\&view=article\&id=31\%3Ameasuringdevelopment-holding-infinity\&Itemid=2>. Acesso em: 05 ago. 2011.

\section{COMMUNITY DEVELOPMENT RESOURCE} ASSOCIATION. Monitoring and Evaluation in Learning Organisations: transparency of process. Cape Town: Community Development Resource Association, 2006. Annual Report 2006.

Disponível em: <http://www.cdra.org.za/> . Acesso em: 05 ago. 2011.

CRAWFORD, L.; POLLACK, J. Hard and Soft Projects: a framework for analysis. International Journal of Project Management, v. 22, n. 8, p. 645-653, 2004.

EUROPEAN COMMISSION. Project Cycle Management Handbook. Version 2.0. March 2002.

FORMOSO, C. T.; MIRON L. I. G. (Coord). Contribuições Para a Avaliação de Programas Integrados de Habitação de Interesse Social. Porto Alegre: NORIE/UFRGS, 2008. Relatório de Avaliação Intermediária do PIEC.

GRANT, H. H. Logical Framework (logframe) Methodology: a practical approach. The Project Development Institute, 2007. Disponível em: $<$ http://www.izmirab.gov.tr/WEB/documents/kutu phane/LOGFRAME.pdf> . Acesso em: 05 ago. 2011. 
JONES, R. E.; DECKRO, R. F. The Social Psychology of Project Management Conflict. European Journal of Operational Research, v. 64, n. 2, p. 216-228, 1993.

KOSKELA, L. J.; HOWELL, G. The Underlying Theory of Project Management Is Obsolete. In: PROJECT MANAGEMENT INSTITUTE RESEARCH CONFERENCE, 2002, Seattle. Proceedings... Seattle, 2002.

LUNGO, M. Macroproyectos Urbanos: desafio para las ciudades latinoamericanas. Land Lines, v. 14, n. 4, out. 2002.

MIRON, L. I. G. Gerenciamento dos Requisitos dos Clientes de Empreendimentos

Habitacionais de Interesse Social: proposta para o Programa Integrado Entrada da Cidade em Porto Alegre, RS. 350 f. 2008. Porto Alegre. Tese (Doutorado em Engenharia Civil) - Programa de Pós-graduação em Engenharia Civil, Universidade Federal do Rio Grande do Sul, Porto Alegre, 2008.

PREFEITURA MUNICIPAL DE PORTO

ALEGRE. Plano Diretor de Desenvolvimento Urbano e Ambiental. Porto Alegre: PMPA/SPM, 1999.
REISS, G. et al. Gower Handbook of Programme Management. Hampshire, UK: Gower Publishing, 2006.

THORP, J. The Information Paradox: realising the business benefits of information technology. Toronto: McGraw-Hill, 1998.

TURNER, J. R.; COCHRANE, R. A. Goals-andMethods Matrix: coping with projects with illdefined goals and/or methods of achieving them. International Journal of Project Management, v. 11, n. 2, p. 93-102, 1993.

ULTRAMARI, C.; REZENDE, D. A. Grandes Projetos Urbanos: conceitos e referenciais. Ambiente Construído, Porto Alegre, v. 7, n. 2, p. 7-14, abr./jun. 2007.

WILLIAMS, T. Modelling Complex Projects. Chichester: John Wiley \& Sons, 2002.

WINTER, M. et al. Directions for Future Research in Project Management: the main findings of UK government-funded research network. International Journal of Project Management, v. 24, n. 8, p. 638-649, 2006.

Revista Ambiente Construído

Associação Nacional de Tecnologia do Ambiente Construído

Av. Osvaldo Aranha, 99 - 3o andar, Centro

Porto Alegre - RS - Brasil

CEP 90035-190

Telefone: +55 (51) 3308-4084

Fax: +55 (51) 3308-4054

www. seer. ufrgs. br/ ambienteconstruido

E-mail: ambienteconstruido@ufrgs.br 